\title{
Roundtable Global Book Markets
}

\author{
A Conversation with Susanne Lange (Berlin/Translator), Diego \\ Lorenzo (Buenos Aires/Programa SUR), Benjamin Loy \\ (Universität Wien), María Lynch (Barcelona/Casanovas \& \\ Lynch), and Sandra Pulido (Bogotá/Bogotá Book Fair)
}

Hannover, July 2, 2019

Participants: Susanne Lange (SL), Diego Lorenzo (DL), Benjamin Loy (BL), María Lynch (ML), Sandra Pulido (SP), Público (P)

BL: El propósito de esta conferencia es promover el diálogo entre académicos y profesionales del mercado del libro: ¿cómo definirían sus funciones dentro del mercado literario, mercado del libro?; y también, ¿cómo han cambiado quizás esas funciones, las tareas, las exigencias, que tienen que enfrentar desde que ustedes entraron a sus respectivas posiciones laborales?

ML: De mi función ya se ha hablado bastante in extenso en las conferencias y creo que ha quedado clara la función comercial, la de gestión y asesoramiento legal, la venta de derechos subsidiarios y el aumento de los ingresos de los autores. Haciendo honor a mi carrera anterior de bióloga, suelo describir mi función como la de una enzima, que es un elemento catalizador de una reacción química que a veces se daría de todos modos, aunque mucho más despacio, pero otras no se daría jamás. La enzima se ocupa de unir las dos piezas involucradas para que se contacten; en el caso de la edición, que se publique un libro.

Me gustaría señalar cuatro puntos que creo que no se han desarrollado mucho con respecto a la función del agente actualmente. El primero de todos, $\mathrm{y}$ siguiendo el orden cronológico, es el de la primera lectura del manuscrito, en el entendido de que es un momento muy frágil para el autor y para la psicología del autor. La primera lectura del agente es una lectura más cómplice que la del editor o en la que el autor tiene menos miedo al rechazo, porque parte de un contrato preexistente que consiste en que el agente siempre va a defender los intereses y los deseos del autor. Aparte de esa complicidad, sí creo que en muchos aspectos, y a lo largo de la carrera del autor, el agente participa del seguimiento de una idea y de su desarrollo; pensar, por ejemplo, desde dónde se escribe, el punto de vista, los personajes, la trama . . . Son momentos del desa- 
rrollo de una obra, en las que normalmente participamos y aconsejamos los agentes. Hablo por mi experiencia, al menos, ya que hay tantos modelos de agencias como modelos de editoriales. Creo que no se ha hecho quizás suficiente hincapié en esta faceta del trabajo del agente literario como primer lector $\mathrm{y}$, en segunda instancia, también como oteador o como scout de autores. Me refiero, por ejemplo, al caso de autores latinoamericanos que a menudo están publicados por editoriales independientes, que hacen una labor muy interesante de crear una cantera de autores jóvenes en sus países y que muchas veces no tienen los recursos suficientes ni la capacidad de internacionalizarlos.

El segundo punto, que creo que además ha cambiado mucho en los últimos diez o quince años, tiene que ver con las estrategias de difusión de los autores dentro de la lengua española, no tanto de internacionalización o traducción, sino que a veces es muy difícil que a un peruano lo lean en México, que a un argentino lo lean en Colombia o a un español en Argentina. Conseguir que un autor en lengua española se lea en todo el territorio de habla hispana, que es muy amplio y muy grande, a veces es un gran reto. En ese aspecto normalmente yo aplico dos estrategias: cuando es una editorial que publica globalmente en lengua española, ya sea a mediana escala, como el caso de Anagrama, o de algún grupo, si cedo los derechos mundiales, después cumplo una labor bastante ardua de perseguir como un sabueso al editor para que el libro circule, se publique, se invite al autor y se promocione en todo el territorio. En otras ocasiones, lo que hago es atomizar los derechos de esa obra. Trabajo mucho con editoriales independientes en cada uno de los territorios que aseguran una publicación más específica para el territorio y el mercado, además de ser más competitivas en el precio de venta. También quería dejar en claro que muchas veces son estrategias que no comportan beneficios económicos. Es decir, evidentemente cuando trabajo con editoriales independientes los anticipos van a ser muchas veces simbólicos, pero la diferencia que significa que un autor se publique en una edición de 500 o 1000 ejemplares en Bolivia, con el trato específico que dará al libro ese editor es mucho mayor que el rendimiento económico. Digamos que, cuando trabajas con autores literarios, como es mi caso, a medio o largo plazo uno no espera recibir un rédito económico inmediato, sino que los ciclos son un poco más largos.

El tercer punto, que creo que es importante, es que el agente cumple una función de fidelidad, constancia y continuidad, que ya no existe tanto en la figura del editor. Ya sea porque los autores cambian de editor o porque los editores cambian de editorial, como ocurre cuando un editor cambia de sello editorial y deja atrás a los autores que ha contratado. Si uno mira los catálogos de los agentes españoles, hay autores que han estado con Balcells, no sé, cuarenta años, es decir, prácticamente toda su carrera la han hecho con ella. En mi 
caso, con autores de mi generación, en ocasiones la figura del agente se acerca a la del albacea; es una figura que ha vivido la gestación de una obra desde que es una idea, conoce los libros que se han abortado, los proyectos que no han salido, la concepción de una obra en general, en el sentido amplio y no de un libro en particular, y que también reúne la obra de un autor cuando practica distintos géneros, cosa que no necesariamente hacen las editoriales puesto que quizá no todas las obras encajan en su línea editorial. Actualmente represento autores que son poetas y novelistas, o son ensayistas y novelistas . . y en esos casos hay varios editores que tratan con un autor, pero digamos que la figura aglutinadora sería la del agente. A veces, sobre todo cuando se trata de internacionalizar, se necesita de un montón de elementos que tienen que encajar para poder hacerlos funcionar en sinergia.

El último aspecto es el del trabajo que ejerce el agente postventa de los derechos, tanto en español como en el extranjero. Trabajamos mucho con los traductores, no tanto en la edición de la traducción, que es un trabajo enteramente del editor, sino en asesorar a los editores en cuanto a posibles traductores, por ejemplo. Puede parecer algo muy obvio, pero no lo es tanto. Opinar sobre pruebas de traducción, títulos, cubiertas, circular información de todas las ediciones extranjeras; compartir cómo se ha publicado un libro en distintos países, y qué estrategias se han utilizado en cada uno de ellos. También aconsejamos y asesoramos en los viajes y en la promoción a los autores. Ahora es muy importante en la carrera de un autor que tenga una trayectoria internacional y muchas veces un autor que todavía no ha dado ese paso no distingue si un festival italiano es importante, o no, si vale la pena hacer el viaje. Pienso también, por último, que lo que se desarrollará en el futuro es también la venta de los derechos audiovisuales, de cine y televisión. Es algo que ha cambiado radicalmente en los últimos, diría, tres años, de forma exponencial.

BL: Si la agente es la enzima, ¿qué sería la traductora dentro del ecosistema literario?

SL: Estamos en el otro lado, no al comienzo, sino casi al final, pero hay cosas paralelas, me parece, porque también los traductores son a veces oteadores que buscan textos interesantes. Para las editoriales de su país muchas veces actúan un poco como los agentes, proponiendo cosas, incluso haciendo pruebas de traducción, todas cosas que hacen también los agentes, pero a los traductores nadie les paga por eso. A veces también trabajan el texto, las novelas, hoy en día llegan muchos en forma de manuscrito, normalmente se trabaja con libros ya publicados, pero ahora muchas veces te llegan textos que no se han publicado y las traducciones salen al mismo tiempo que los libros. En este caso el traductor no es el primer lector que mira un texto en ese estado tan frágil del 
que hablaste, pero sí lo mira tal vez tan minuciosamente como nadie, ningún editor o lector, lo puede mirar.

Nadie mira un texto tan minuciosamente, palabra por palabra, como un traductor. Se supone que en las editoriales de habla española hay un corrector o un lector que trabaja los textos, pero a veces se tiene la impresión de que ni el autor lo ha leído una segunda vez, lo que seguramente no es cierto, pero muchas veces se tiene la idea de que alguien hubiera debido darse cuenta de ciertas incongruencias o imprecisiones o repeticiones, pero no. Y cuando el lector de la editorial mira la traducción pueden surgir incluso más cosas para corregir, es un trabajo tan minucioso. Si el original no se ha publicado aun, está bien, se puede corregir todavía, pero cuando ya ha salido en español, a los escritores no les gusta a veces cambiar, porque después la traducción difiere del original.

Al mismo tiempo me parece que la traducción conlleva una responsabilidad muy grande hacía el autor y hacía tu propia lengua. Ya Don Quijote dice, cuando en la segunda parte se entera de que la gente ha leído la primera parte y que incluso han salido traducciones: "una de las cosas que más debe de dar contento a un hombre virtuoso y eminente es verse, viviendo, andar con buen nombre por las lenguas de las gentes, impreso y en estampa. Dije con buen nombre, porque, siendo al contrario, ninguna muerte se le igualará”. Y eso es verdad: si la primera traducción o también las siguientes de una obra no son cuidadosas, es como si estuviera enterrado vivo el escritor y la obra. Muchas veces los editores, o los agentes, subestiman esta importancia, esta responsabilidad de la traducción y no quieren invertir demasiado en ella. También hay editoriales que sí, que la toman muy en serio, pero hay, por ejemplo, pequeñas editoriales de poesía, que hacen un trabajo magnífico sacando a poetas que nadie ha querido publicar, pero no cuidan el aspecto de la traducción, tal vez porque no tienen dinero para financiarla, pero es una lástima, porque si no salen en buenas traducciones, bueno, están como . . . si no existieran en la lengua de la traducción. Pienso que los traductores deberían tener este compromiso con su propia lengua y no introducir automáticamente giros de la otra y echarla un poco a perder de esta manera. Realmente se trata de reescribir una obra y para eso hay que estudiar mucho la propia literatura, no solamente la extranjera y el mercado extranjero, los libros extranjeros, sino juntarlos con la tradición literaria propia.

BL: ¿Y en el caso de la ferias del libro?

SP: Comienzo por decirles que la Cámara del Libro en Colombia es el gremio que agrupa editores, libreros y distribuidores de libros en el país, a diferencia de otras cámaras en América Latina. Pensando en la internacionalización, nos asociamos estos últimos dos años con la Biblioteca Nacional y el Ministerio de Cultura para sacar adelante: Reading Colombia, un programa de becas de tra- 
ducción. Además, representamos a Colombia en ferias internacionales como Bolonia, Frankfurt y Guadalajara, esta última con apoyo del Gobierno Nacional.

Pensando en el fortalecimiento al interior del país, creamos una red de ferias de libro en Colombia inspirada en un grupo de ferieros, del que la Feria del Libro de Bogotá hace parte. La FILBa y la FIL también están. Es un trabajo principalmente colaborativo. Lo que nos inventamos en Colombia ha tenido muy buenos resultados. Hoy somos 13 ferias del libro que nos comunicamos permanentemente, preguntamos desde datos de un autor, hasta temas de logística. Ha sido un trabajo muy bonito, compartiendo desde la generosidad del conocimiento. Una muestra de que sí se puede hacer un trabajo colaborativo en promover la lectura y el libro en Colombia.

Ahora hablando principalmente de la FILBo, como ya algunos saben es una feria con una programación cultural reconocida a nivel internacional. En los últimos años hemos tenido la oportunidad de diversificar el programa a contenidos como ciencia, música, gastronomía, cine, entre otros.

En el punto literario y trabajando de la mano de la ASEUC, sacamos este ano un proyecto que se llama FILBo Debates, queríamos mejorar la participación de estudiantes universitarios en la feria porque justamente queríamos jugar con la idea de generar debates, entonces, un invitado internacional, un profesor universitario y un periodista hablaban sobre uno de los temas pilares de la feria: género, territorio, medio ambiente, entre otros. Fue muy interesante ver que llegaron estudiantes de colegio, público general, cuando habíamos pensado en llegar solo al público universitario.

BL: Muy transversal todo lo que implica, también siempre con la perspectiva de crear un cierto discurso de la representación nacional, lo que evidentemente en las ferias y en el concepto de los países invitados siempre tiene papel importante.

DL: Claro, para el caso de la Argentina, el Programa SUR, que es un programa de subsidio a las traducciones fruto de una invitación de honor a la Feria de Frankfurt en 2010, es un programa 100\% estatal, es decir, que está muy ligado a una concepción de lo nacional en términos de una política cultural, eso es lo bueno, y al mismo tiempo está ligado a una cultura política, lo cual lo deja a merced de cambios y coyunturas, eso es lo menos bueno.

Quiero decir que navegamos en esa tensión, pero definitivamente en cuanto a su intervención en el mercado del libro como una política está muy ligado a lo nacional, a la presencia en ferias, a una imagen de la Argentina en el exterior, etc., El programa es técnicamente muy similar a otros programas, que se han tomado como modelos y nuestro nacimiento, por estar muy ligado a la feria de Frankfurt y al mercado alemán, fue adoptado en el marco de la Cancillería argentina y, logrando sortear cambios de gobierno hoy, luego de once 
años de duración del programa, ha permitido, en comparación con otros programas latinoamericanos, una permanencia y una ampliación que lleva 1360 obras a 45 idiomas en 50 países.

No me parecen desdeñables esas cifras ya que si se piensa lo que se traducía o lo que se conocía como cifra de traducción previa a la existencia de este programa en Argentina, es un fenómeno sorpresivo y sobre el cual sería lícito hacer un análisis. En principio, nosotros como gestores y burócratas culturales, no reflexionamos académicamente sobre nuestra propia concepción de trabajo, no hacemos eso ni es nuestra competencia, pero cuando empezamos a leer bibliografía académica, informes y las pocas estadísticas internacionales que existen de manera consolidada, o empezamos a escuchar a los profesionales del sector, e incluso cuando vengo a estos ámbitos, la verdad es que miro para atrás y digo, bueno, es un raro milagro esto que hemos logrado; dejemos que lo expliquen otros, pero definitivamente lo que quiero decir es que estas herramientas puestas al servicio de la internacionalización del libro argentino, en el ámbito estatal, en el caso argentino puntualmente, han funcionado bien.

Como es una política de promoción en sentido amplio, aun cuando obviamente tenemos que definir ciertas esencias, está abierto a todo el sector editorial; el Programa SUR no tiene restricciones ni de género ni de autores, esa es la parte buena de la cultura política, el Estado no es árbitro del gusto ahí. Como decía, es una política que interviene en el mercado facilitando el costo de la oferta del libro argentino, específicamente el costo de la traducción. En Argentina todavía prevalece una tradición - bien fundada, dicho sea de paso- de una cultura exportadora del libro muy ligada al libro físico.

Ahora bien, el derecho como un bien de exportación, si bien probablemente no da grandes números, indiscutiblemente genera prestigio en los catálogos, es una ampliación de paradigma que el Estado puede ayudar a consolidar y representa un símbolo de lo nacional en el sentido positivo: posicionar y defender un capital literario nacional en un mercado muy globalizado y altamente jerarquizado como es el campo de la edición internacional.

Por último, creo decididamente que una política pública debería nutrirse de la reflexión de la academia para empezar a generar círculos virtuosos de mejora en la política pública. Por lo que se alcanza a ver por ahí, no siempre están esas intersecciones, nosotros lo hemos buscado y logrado con un equipo de investigadores que están en Argentina como Gustavo Sorá o Alejandro Dujovne, quien ahora participa del comité de traducciones. Digo que lo hemos buscado también para que desde la Academia se entienda que la burocracia cultural tiene sus bemoles, que a veces se puede reflexionar desde un ámbito académico de manera muy precisa, pero cuando lo querés implementar en la gestión hay un montón de meandros administrativos que no lo permiten o lo retrasan, porque 
suele ocurrir que alguno no quiere firmar esto o aquello, y en la base de estos engranajes desde luego están las discusiones administrativas y políticas sobre el presupuesto.

BL: ¿Observamos, al igual que en el caso de los escritores, una creciente profesionalización también del mercado literario y de sus diferentes sectores? Tenemos cada vez más carreras especializadas, por ejemplo de edición, los numerosos fellowships que hay en las ferias, las becas de traducción, etc., ¿cómo juzgarían ese desarrollo?

ML: Bueno, yo creo que lo que hay es más figuras intermediarias, que antes no existían. Antes Michi Strausfeld hablaba con Manuel Puig directamente, y ahora casi siempre está el agente de por medio. Los scouts se han convertido también en una pieza muy importante . . y también estoy de acuerdo con lo que decía Diego Lorenzo, que los programas de ayuda a las traducciones son vitales para que los libros se traduzcan. Son realmente importantes sobre todo cuando se trata de autores literarios, ya que de nuevo es una apuesta a largo plazo, en la que los editores tienen que esperar a que el ciclo de un retorno.

DL: El Programa SUR, en la práctica, se funda en el pilar del traductor y del agente, para finalmente poder generar después una fidelización del editor extranjero, porque generalmente una traducción trae a otra, ese efecto multiplicador, que se ha puede observar en las reflexiones de Pascale Casanova o Johan Heilbron en el Programa SUR, es claramente comprobable.

Se confirma sobre todo que hay "lenguas faro", si se traduce al inglés luego de esto va a ocurrir que la obra va a ir hacia otros mercados, y resulta patente que los mercados se miran entre sí. Es decir, todo lo que se lee en cierta bibliografía sobre la geopolítica de la traducción es cierto y resulta patente en la gestión, y observamos que se genera a partir de ciertos agentes claves, mediadores insoslayables que en nuestro caso son los traductores y los agentes.

SP: A mí sí me gustaría que la academia tuviera una mayor participación en toda la profesionalización del libro en Colombia, existe una universidad con pregrado, que es la Javeriana, con énfasis en editorial, hay un par de diplomados, está la Maestría Caro y Cuervo, pero creo que si hubiera más opciones esto permitiría que se enriquezca más. Entonces creo que se están haciendo esfuerzos desde Colombia, y sin duda alguna la profesionalización, los escritores también, están saliendo escritores muy interesantes, de editores, editoriales independientes, librerías independientes que están haciendo un trabajo maravilloso.

BL: Nos quedamos quizás un momento en general con la función de las ferias del libro, porque quería llegar a eso también, no son solamente lugares de nego- 
ciación de derechos, sino básicamente de comunicación, de hablar sobre libros, generar un discurso, debates en torno al libro: la pregunta sería ¿si reemplazan en cierto sentido las ferias del libro como, o diversifican quizás el conjunto de instancias comunicativas con respecto al libro? ¿Y cuáles fueron experiencias que ustedes mismos tuvieron con las diferentes ferias y sobre todo cuando había países invitados, como Argentina 2010 y quizás Brasil en el 2013 en Frankfurt, y cuáles podrían ser posibles expectativas para España ahora en 2021?

SP: Pues, cada feria es distinta y tiene una personalidad diferente. Bogotá es ciudad capital, por ende tiene la cercanía con la mayoría de los medios de comunicación del país. Con mucho esfuerzo, una gran campaña 360, todos los medios del país están hablando de lo que está pasando en la FILBo. Y tiene un impacto directo al invitado de honor pues es la principal novedad que comunicamos masivamente. Intentamos hacer adopciones de autor en colegios y universidades, descentralizamos la programación del recinto ferial a toda la ciudad, y ahora lo estamos llevando al resto del país.

La FILBo y las demás ferias del libro de Colombia están siendo determinante en un país que tiene muy pocas librerías. Seguimos trabajando como gremio y como feria en el fortalecimiento de la cadena del libro, en especial en la distribución y comercialización que es tan débil en el país. FILBo emprende es un resultado concreto que busca encontrar, poner a prueba y fortalecer nuevas ideas de negocio editoriales.

DL: Nosotros participamos como país invitado de honor, en un ciclo muy intenso, 2010 Frankfurt, 2014 Guadalajara, luego 2016 Bogotá. Genera mucha necesidad de presupuestos, mucha inversión ser país invitado de honor. Para nosotros, creo que esa inversión valió la pena porque el mercado alemán se ha mantenido: el alemán es la segunda lengua más requerida en el marco del Programa SUR dentro de estas 45 lenguas que tenemos, y básicamente nuestro 65\% de exportación de derechos va a Europa, o sea, que eso está marcado y nos ha funcionado cuantitativamente. Después, sabemos que hay controversias respecto a los criterios de presentación de nuestra imagen en el exterior, pero está más ligado al ámbito periodístico y, por ende, tiene más repercusión nacional que en términos de repercusión internacional, lo cual - dicho sea de pasosería más deseable.

ML: Siento ser la pesimista de la mesa, pero en mi experiencia no supone una cosa a largo plazo. Ser invitado de honor en la feria de Frankfurt implica que todos los alemanes se vuelcan a comprar autores del país invitado, pero no necesariamente se mantienen las publicaciones ni hay continuidad. El resto de editores de todo el mundo que están en la feria en Frankfurt no necesariamente 
prestan atención a esos autores, porque están preocupados por las dinámicas de la propia feria, que generalmente van en paralelo al país invitado. Además suelen ser polémicos: yo estuve cuando Cataluña fue país invitado en Frankfurt y se discutió y criticó mucho la selección. Solo participaron los que escribían en catalán, a pesar de que se discutió muchísimo si tenían que estar también los catalanes que escribían en español. En el caso de Argentina también resultó polémico porque se les acusó de hacer una selección basada en un criterio político, de apoyo al gobierno del momento. En cambio, creo que sí es muy interesante que los autores vayan a las ferias y que estén mezclados con los autores locales.

SL: Para volver un momento al aspecto de la profesionalización: los traductores se han profesionalizado bastante hace un tiempo ya, hay el Fondo de Traductores, el Deutsche Übersetzerfonds, que organiza muchos seminarios y talleres, entre ellos algo que me parece muy lindo, talleres que se llaman viceversa, en los cuales participan traductores españoles y latinoamericanos que traducen del alemán al castellano y al revés, seis de cada lengua. Se encuentran en Argentina, en México, en España. También tenemos un foro de traductores: estamos en contacto y si hay un problema de traducción, alguien hace la pregunta al foro: un intercambio realmente bueno y efectivo también.

Sin embargo, aunque haya muchos seminarios y talleres, el interés está menguando. Tal vez, para hacer la conexión con la universidad, eso tiene que ver un poco con las universidades, porque cuando ocupaba la cátedra Schlegel en Berlín para estudiantes de literatura comparada al nivel de máster, todos tenían mucho interés en la traducción, pero ninguno realmente tenía experiencia en analizar un texto, el lenguaje de un texto. Sabían muy bien las lenguas extranjeras, pero no sabían analizar un texto lingüísticamente. Así que comencé con un análisis de textos en alemán, antes de hablarles de la traducción, para que pudieran ver de qué manera tal y tal autor forma su estilo y por qué se expresa de esta manera y no de otra. Me parece que es algo que hoy en día ya no tiene tanto lugar en los estudios de filología, los estudiantes se ocupan de motivos, de sociología, de muchas cosas, pero no realmente del lenguaje literario de un texto. Puede que eso cree traductores que realmente piensen que hay que traducir una trama y no vean la estructura lingüística del texto. Y hay que llegar a este nivel para traducir bien.

ML: Yo tengo una pregunta para Susanne Lange también respecto a la profesionalización, porque tengo entendido que lo que ha cambiado en Alemania son las condiciones de los traductores. Hace unos años que se empezó a reconocer un royalty para los traductores, las tarifas también han mejorado. Ha habido un cambio paradigmático también. 
SL: Sí, hace ya un tiempo que los traductores participan en la venta de las obras. Pero considerando, por ejemplo, la traducción de la poesía, en eso no hay ninguna relación entre el trabajo y lo que pagan. Es una desproporción completamente absurda. Han cambiado las condiciones, pero claro que todavía hay bastante camino por recorrer ... .

\section{PREGUNTAS DEL PÚBLICO}

P1: Tenía una pregunta para María Lynch, sobre todo al respecto del primer punto que comentabas de la agente literaria como primera lectora del manuscrito. Y me gustaría quizás que fueras un poco más detallista, en qué se traduce, por ejemplo, en el archivo de García Márquez antes de, bueno siempre te encuentras con varias versiones de sus obras, y luego tienes una versión Balcells, que él le envía a ella . . c correspondencia, en la que ella tiene, por ejemplo, un debate muy precioso con García Márquez, en que le insiste en que el nombre para contarla es gramáticamente incorrecto, le da una lista escrita con mucha gramática, para explicarle que no puede poner contarla, porque eso viola las reglas de la gramática . . . entonces, en tu caso, ¿a qué se traduce ese ser lectora?, ¿consideras que lees y buscas erratas, inconsistencias?

ML: La labor como lectora depende mucho de la relación que tengas con ese autor y de la necesidad que tenga. A Javier Marías no le toco ni una coma, no, ni me atrevería seguramente (tampoco su editora), pero hay otros autores con los que tengo otra relación. También depende mucho del libro, hay autores que están muy inseguros con un libro y luego están convencidos con otro; he tenido experiencias de cambiar la estructura de una novela, como La forma de las ruinas, que tenía capítulos alternos y que a mí no me acababan de funcionar cuando los leí. Sugerí que extrajera una de las tramas de la novela, que estaba en capítulos alternos, y que los reuniera en una suerte de novela dentro de otra novela. Hay muchos niveles en los que uno puede intervenir y a veces no es más que una cuestión puramente psicológica: que el autor necesita que alguien crea en un libro que nadie más ha leído hasta ese momento. Puede ser tan sencillo como eso, pero es muy importante para que el autor se sienta cómodo con su novela, su ensayo, su libro de cuentos . . .

P2: En el caso de las agencias españolas, uno siempre tiene que preguntar a una agente española ¿cómo se posiciona con respecto a la figura de Balcells?

ML: Yo creo que Carmen Balcells fue imprescindible, no solo para las agencias literarias, sino para el ecosistema editorial español: desde cambiar las leyes, 
hasta la manera en que los autores se independizaron de los editores. Creo que es indiscutible su papel y su valor, no solo en el ámbito español sino en el ámbito mundial. Dicho esto, creo que ella tenía una manera de entender la agencia de su época, y yo la admiro mucho pero también hay cosas que me gusta hacer de otra forma. Por ejemplo, esos intercambios y presiones que hacía con un autor para que publicaran a otro autor, yo no los aplico hoy y además tampoco creo que en el largo término sean buenos.

P3: En el Programa SUR, la pregunta es, ustedes hacen los contratos, la editorial extranjera solicita, se autoriza la traducción, se paga la traducción y ¿qué pasa con los libros después?, ¿ustedes tienen algún seguimiento si esos libros se venden, no se venden?

DL: Como buen argentino, vos sabés que nos cuesta, el largo aliento nos cuesta. Es un vértigo desconocido.

Hablando en serio: hace dos años estamos buscando que se apruebe una encuesta cualitativa para los editores extranjeros, trabajando con el equipo de investigación que mencioné antes: una encuesta en cinco idiomas dirigida a los editores extranjeros, son más de 800 , para efectivamente ver cuál ha sido la suerte o el impacto de los libros que hemos apoyado. Estamos superando los tres millones de dólares, desde un principio hasta ahora, en término de apoyos, es esperable tener algún dato respecto a eso. No tengo la aprobación, es lo que hablábamos antes sobre los meandros administrativos y sus etcéteras.

P4: La figura del bibliotecario en las ferias, me lo imagino que los bibliotecarios funcionan como prescriptores, ¿son importantes y por qué?

SP: Son muy importantes. Hay una biblioteca por cada municipio del país (1524 en 32 departamentos) y una red distrital en Bogotá de 21 bibliotecas que tanto a la ciudad como al país mantienen en una dinámica interesante y necesaria social y culturalmente. Hay muchas historias maravillosas que poco se conocen. Fuera de Colombia conocí el proyecto Bibliotecas Móviles por la Paz. Se hizo durante el gobierno de Juan Manuel Santos con apoyo internacional. El bibliotecario de San Vicente del Caguan contaba cómo se llevó a cabo un intercambio de armas por libros.

Si bien la feria invierte en traer bibliotecarios internacionales para formar a los colombianos, estamos trabajando en visibilizar más las bibliotecas del país, donde en muchos municipios se convierte en el eje cultural. Para mí y para la FILBo cada día son más importantes los bibliotecarios, tanto públicos como escolares. Tienen retos distintos y estamos buscando ofrecerles cada vez mejores contenidos, ofertas y condiciones, tanto a los nacionales como a los internacio- 
nales, para facilitarles su experiencia de la feria, y que estén más cerca con todos los actores de la cadena del libro.

P5: A mí genuinamente me interesa la experiencia de trabajar en las traducciones de lenguas "menores", por ejemplo, hay buenos escritores mexicanos que no están traducidos ni al inglés, ni al alemán, ni al francés, pero están traducidos al islandés, al búlgaro y al turco . . . y eso tiene un significado. ¿Cuál es la dinámica y el entendimiento cuándo, por ejemplo, se acerca un agente a ustedes, o un traductor del búlgaro, vamos a decir, y un mercado que a lo mejor no va a ser rentable, pero que puede tener algún tipo de interés simbólico para el escritor, los están acercando a un escritor por cierta razón . . . ?

DL: Nosotros tenemos un comité de expertos, obviamente, y, desde luego, se dan fenómenos rarísimos en la discusión, porque te aparece una traducción al islandés, y algún experto te dice, por poner el ejemplo de Roberto Arlt: "pero escúchame, cómo van a traducir 'rajá, turrito, rajá' al islandés?” En el caso del Programa SUR lo que prevalece es la política de promoción, entendemos que si hay un interés genuino por traducir un autor latinoamericano preferimos que se apruebe para que esté ahí un libro argentino y ver qué efecto multiplicador hay. Pero, así como señalas, hay un montón de casos, de autores argentinos, que no pasan por lenguas centrales, mucho menos por el inglés, y de pronto se van hacia el este de Europa, casi con un efecto cascada, porque evidentemente ahí lo que confirmamos, como dije antes, es que ahí los mercados se miran mucho entre sí, entonces donde empieza uno, efectivamente luego se logra armar un encadanamiento.

ML: Yo promuevo las traducciones en todas las lenguas, no hago diferencias. Mi modelo de negocio, en el caso de las traducciones, no suele ser rentable. El volumen de retorno de un autor es, normalmente, por la lengua española. Hay casos excepcionales de autores que son muy exitosos en el extranjero, pero no es la regla. Las traducciones normalmente son importantes porque es una herramienta de difusión del autor y porque los autores puede que cobren 500 euros por un contrato de traducción al turco, pero la idea de que su libro se traduzca en Turquía les llena de orgullo. No es una relación cuantitativa. Y pongo tanto empeño en que se traduzca al búlgaro como en que se traduzca al francés o al italiano, no hago diferencias en ligas. 
This project has received funding from the European Research Council (ERC) under the European Union's Horizon 2020 Research and Innovation programme Grant Agreement Number 646714.
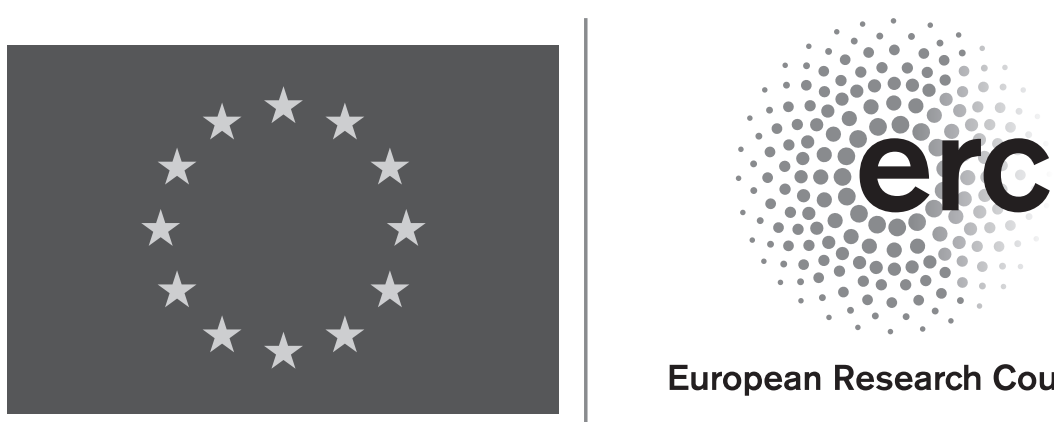

\section{European Research Council}

Established by the European Commission 
